
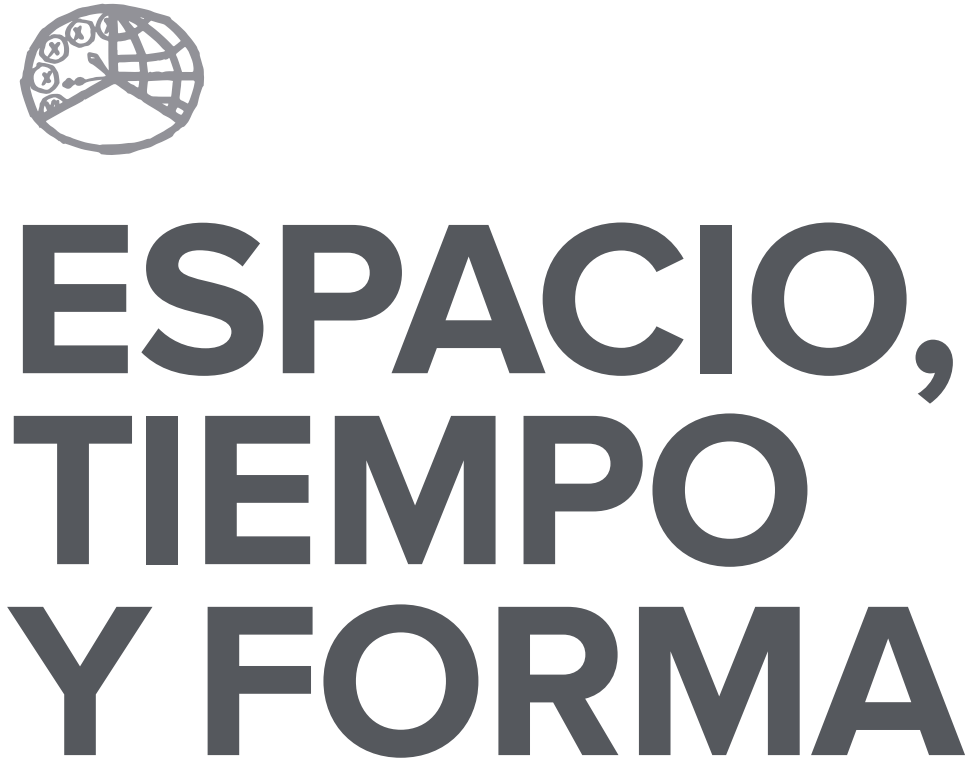

AÑO 2018

ISSN 0214-9745

E-ISSN 2340-1362

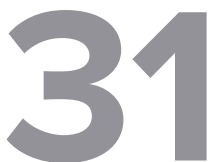

SERIE III HISTORIA MEDIEVAL

REVISTA DE LA FACULTAD DE GEOGRAFÍA E HISTORIA 



\section{ARTÍCULOS · ARTICLES}





\title{
LOS HABICES DE LA VEGA DE GRANADA COMO FORMA DE CONOCIMIENTO DEL REINO NAZARÍ Y SU TRANSFORMACIÓN TRAS LA CONQUISTA: LA ALQUERÍA DE LA ZUBIA
}

\section{THE HABICES OF THE VEGA OF GRANADA AS A SOURCE FOR UNDERSTANDING THE NASRID KINGDOM AND ITS TRANSFORMATION AFTER THE CONQUEST: THE ALQUERÍA OF LA ZUBIA}

\author{
Sandra Suárez García ${ }^{1}$
}

Recepción: 2017/12/27 · Comunicación de observaciones de evaluadores: 2018/03/12 . Aceptación: 2018/03/13

DOI: http://dx.doi.org/10.5944/etfiii.31.2018.20745

\section{Resumen ${ }^{2}$}

Analizamos La Zubia, una de las alquerías de la Vega de Granada, a través del estudio de sus bienes habices en los Libros de 1503 y I505, en conjunto con su correspondiente Libro de Apeo (I570), para conocer mejor sus características socio-económicas, el régimen de propiedad, su configuración interna y algunos rasgos destacados de su población, toponimia y el registro de pagos. Encontramos una localidad preponderante sobre otras alquerías de los alrededores, dedicada principalmente al regadío. Consta de una suficiente red interna de comunicación, y sus bienes habices son numerosos pero marcados por una eevada parcelación y extensión limitada. Localizamos, asimismo, algunos de sus pagos a través de la cartografía y la toponimia.

1. Contratada predoctoral de la Universidad de Granada. C.e.: sandrasuarez@ugr.es

2. Este artículo ha sido elaborado en el marco del Proyecto de I+D «La propiedad aristocrática en la Granada nazarí y su traspaso a la sociedad castellana después de la conquista (siglos XIII-XVI)» (HAR2015-64605-C2-2-P), del Ministerio de Economía, Industria y Competitividad. Parte de la Beca de Iniciación a la Investigación para estudiantes de máster del Plan Propio de la Universidad de Granada. 


\title{
Palabras clave
}

Habices; La Zubia; alquería; Vega de Granada; conquista; nazarí.

\begin{abstract}
We will analyze La Zubia, one of the alquerías (rural communities) of the Vega of Granada, in the light of the habices (pious endowment) of 1503 and I505, together with its corresponding books of apeo (cadastre), to determine its socio-economic characteristics, its system of ownership, its internal configuration and some outstanding features of its population, toponymy and record of estates. We find a site that prevails over the other alquerías of the area, and which is mainly dedicated to irrigation agriculture. It has a sufficient internal communication network, and its habices are numerous but marked by considerable division of lots and limited lot extension. We will also identify some of its estates through cartography and toponymy.
\end{abstract}

Keywords

Habices; La Zubia; Alquería; Vega of Granada; Conquest; Nasrid. 


\section{INTRODUCCIÓN}

\subsection{OBJETIVOS Y MÉTODOS}

El presente trabajo busca un acercamiento al estudio de la Vega de Granada, y especialmente de la alquería de La Zubia, a través de dos fuentes de gran interés como son los Libros de habices de 1503 y 1505 . El primero de ellos editado por Pedro Hernández Benito en $1990^{3}$ y el segundo por María del Carmen Villanueva Rico en $\mathrm{I}^{6} 6 \mathrm{I}^{4}$. La combinación de ambos escritos, junto a otras fuentes como los Libros de Apeo (siglo XVI), ofrecen una información inestimable para conocer un espacio geográfico en transición entre el mundo nazarí y el nuevo Reino de Granada, bajo el dominio castellano. Los bienes habices se han convertido en una herramienta clave para el conocimiento de este espacio geográfico tan particular, y gozan ya de una larga trayectoria en la investigación medievalista, pudiéndose citar autores tan relevantes como la propia Villanueva Rico ${ }^{5}$, Carmen Trillo ${ }^{6}$ o Manuel Espinar7.

Nos hemos decantado por centrar nuestro análisis en una única alquería debido al gran caudal de datos que aportan las fuentes, puesto que un análisis pormenorizado de todas las localidades de la Vega necesitaría de un estudio mucho más extenso y prolongado. Así, a través de la recopilación de datos, su tabulación, organización y análisis, pretendemos obtener un mejor conocimiento de La Zubia entre finales del siglo $\mathrm{XV}$ y principios del XVl. Asimismo, compaginaremos este análisis de fuentes con la lectura de textos bibliográficos de relevancia como los estudios realizados hasta el momento sobre bienes habices, la sociedad, la demografía y la economía granadinas entre el período medieval y moderno.

Para ello describiremos en un primer lugar las características de las dos fuentes principales que emplearemos, para posteriormente hacer una concisa aproximación al papel de los legados píos en el Islam. A continuación, se ofrecerán algunos datos de interés para conocer los habices originados en el reino nazarí y su evolución bajo la corona castellana. Finalizaremos con el análisis realizado

3. Hernández Benito, Pedro: La Vega de Granada a fines de la Edad Media según las rentas de los habices. Granada, Diputación Provincial de Granada, 1990.

4. Villanueva Rico, María del Carmen: Habices de las mezquitas de la ciudad de Granada y sus alquerías. Madrid, Instituto Hispano-Árabe de Cultura, 1961.

5. También es muy relevante su recopilación de los habices urbanos de 1527: Villanueva Rico, María del Carmen: Casas, mezquitas y tiendas de los habices de las Iglesias de Granada. Madrid, Instituto Hispano-Árabe de Cultura, 1966.

6. Esta autora ha trabajado con libros de habices de 1501 y 1502. Véanse: TRILLO SAN JOSÉ, Carmen: La Alpujarra medieval según las rentas de los bienes habices. Granada, 1988 y TRILLO SAN JosÉ, Carmen; Hernández Benito, Pedro: «Topónimos de la Alpujarra según un manuscrito de rentas habices», Miscelánea de estudios Árabes y Hebraicos (MEAH), $n^{\circ} 37,1$ (1994), pp. 285-306.

7. Se trata de uno de los mayores expertos en habices granadinos. Citaremos solo algunas de sus obras, vinculadas directamente a los habices de la Vega de Granada: Espinar Moreno, Manuel: «Noticias para el estudio de la alquería de Gójar. Bienes habices», Cuadernos de Estudios Medievales y Ciencias y Técnicas Historiográficas (CEMyCTH), $\mathrm{n}^{\circ} 10-11$ (1983), pp. 105-148 o Espinar Moreno, Manuel: «Notas sobre la alquería de Cájar (1505-1547)», en CEMyCTH, nº14-15, 1985-1987, pp. 47-60. 
sobre las tierras de La Zubia y algunas hipótesis extraídas de nuestro estudio, a modo de conclusión

\subsection{LAS FUENTES: LOS LIBROS DE HABICES DE 1503 Y 1505}

En La Vega de Granada a fines de la Edad Media según las rentas de los habices, Hernández Benito analizó tres documentos, todos ellos procedentes del Archivo General de Simancas, concretamente del legajo 90-2 ${ }^{\circ}$ de la Escribanía Mayor de Rentas. ${ }^{8}$ Es el primero de los mismos el que nos interesa, pues se trata de un Libro de habices de beneficencia que, como bien apunta Hernández Benito, recoge legados para pobres, cautivos, hospitales, escuelas y casas de ablución. ${ }^{9}$ Es Juan Porres, el tesorero de Vizcaya, el encargado de dar relación de estos bienes, si bien delega el trabajo en Pero Gutiérrez. Estos son los únicos habices que la corona castellana guardará para sí, puesto que se habían dado en merced aquellos bienes dedicados al «interés común» al ayuntamiento de Granada, y los que habían pertenecido a mezquitas se entregan a la Iglesia granadina. ${ }^{\text {IO }}$

En los Habices de las mezquitas de la ciudad de Granada y sus alquerías, Villanueva transcribe un manuscrito de $\mathrm{I} 747$, traslado de un libro original de 1505 que se encuentra en el Archivo Histórico Diocesano de Granada (AHDG). La autora apunta, además, que se ha encontrado un documento que debe ser el original u otro traslado más antiguo, fechado en 1506, del mismo libro de habices, en el Archivo de la Catedral de Granada. ${ }^{\text {II }}$ Se trata, en todo caso, de los legados entregados al arzobispado de Granada, que con anterioridad habían pertenecido a «las fábricas, alfaquíes y almuédanos de todas e qualesquier mezquitas y aljamas que avía en esta dicha ciudad y su Reyno» ${ }^{\mathrm{I} 2}$.

En ambos casos se incluyen bienes urbanos y rústicos de la ciudad de Granada y las alquerías de su Vega. Así, es común encontrarse en el ámbito urbano construcciones como tiendas, casas, molinos, hornos, baños o prensas de aceite ${ }^{13}$. En el entorno rural predominan las hazas de secano, regadío, huertas, jardines y árboles, siendo los más comunes los morales y olivos. Se trata de bienes arrendados a particulares, que cumplen a través de la renta con lo estipulado por el habiz. Aunque se suele desconocer el fundador del habiz, ya que no suele citarse en la documentación, la información se vuelve especialmente rica cuando se da

8. Hernández Benito, Pedro: op.cit., p. 8.

9. Ibidem

10. Idem, p. 27

11. La autora considera más probable que se trate de un traslado que del original de la copia de 1747. Villanueva Rico, María del Carmen: op.cit., pp. 5-6.

12. Idem, p. 18.

13. Idem, p. 2 
el nombre del arrendatario, su profesión, los linderos que tiene cada haza, así como la referencia a otros elementos como el nombre de pagos y la calidad de su tierra, la ubicación de acequias, caminos, fuentes e incluso escuelas, mezquitas u hospitales. Esta relación solo ofrece una imagen diluida de la inmensa cantidad de datos antroponímicos, toponímicos, geográficos y económicos que permite conocer la lectura minuciosa de los habices granadinos.

\section{CARIDAD Y LEGADOS PÍOS/PIADOSOS EN EL ISLAM}

Antes de adentrarnos en el análisis de los bienes habices, debemos de tener en cuenta el papel que tuvieron las instituciones piadosas y la caridad, en modo general, dentro de la sociedad islámica medieval. ${ }^{\mathrm{I}} \mathrm{Al}$ igual que ocurre dentro del cristianismo y judaísmo ${ }^{15}$, existen en el Islam preceptos que apremian al ejercicio de la caridad hacia el prójimo. A pesar de esta semejanza, hay autores como Amalia Quevedo que consideran que la caridad musulmana está más relacionada con la purificación del alma que con la solidaridad en sí. Bajo esta visión, la finalidad última no es el socorro de los desafortunados, sino estrechar la relación con Dios a través del desprendimiento de los bienes materiales, para obtener tras la muerte una recompensa divina, si bien en ello resulten favorecidos sectores marginales de la sociedad. ${ }^{\mathrm{I}}$ Veremos que no todos los investigadores comparten su visión, y que muchos aprecian antes la materialidad del habiz, el prestigio y el beneficio familiar frente al elemento religioso. Entre las formas más comunes de caridad destacan el zakät, la șadaqa y el waqf.

Como afirma Adam Sabra, el zakāt, de carácter obligatorio, es uno de los cinco pilares del Islam, un deber hacia Dios. ${ }^{17}$ En definición concisa de la Encyclopédie de l'Islam, se trata de una «obligation imposée aux Musulmans de verser une certaine proportion de leurs biens légaux au bénefice des pauvres et d'autres groupes prédeterminés». ${ }^{18}$ Es precisamente este grado de codificación coránica del zakāt lo que diferencia la caridad musulmana de la de otras religiones monoteístas. ${ }^{19} \mathrm{Se}$ trata de una limosna ritual o impuesto coránico, dentro de los diferentes tipos de

14. Para una visión general pero relevante de este tema podemos remitirnos a la obra reciente de SINGER, Amy: Charity in Islamic Societies. Cambridge, Cambridge University Press, 2008.

15. En el judaísmo, las propias escrituras hablan de la zedaká (justicia, caridad) y obligan a ser caritativos con viudas, huérfanos, forasteros y ancianos. COHN-SHERBOK, Dan: Breve enciclopedia del judaísmo. Madrid, Itsmo, 2003, p.68 En referencia a esta cuestión, cabe destacar también los estudios de Mark Cohen, como el realizado sobre la comunidad egipicia durante la Edad Media: CoHEN, Mark: Poverty and Charity in the Jewish Community of Medieval Egypt. Nueva Jersey, Princeton Univeristy Press, 2005.

16. Quevedo, Amalia: Mendigos ayer y hoy. Madrid, Ediciones Internacionales Universitarias, 2007, p. 55

17. Sabra, Adam: «Charity, Islamic», en Merı, Josef (ed.): Medieval Islamic Civilization. An Encyclopedia. Nueva York, Routledge, 2006, p.145.

18. Zysow, Aron: «Zakāt», en Bearman, Peri et.alii: Encyclopédie de l'Islam. Vol. 11, Leiden, Brill, 2002, p. 441.

19. Kосничт, Thierry: «God, gifts and Poor People: On Charity in Islam», Social Compass, 56, 1, (2009), p. 99. 
tributo que paga la población musulmana ${ }^{20}$, siendo una de sus funciones principales la purificación de la riqueza. ${ }^{21}$ Durante la Edad Media comienza a difundirse el arabismo «azaque» o «açaque», que podemos encontrar en la documentación castellana. $^{22}$

La șadaqa depende totalmente de la voluntad del individuo por destinar parte de sus bienes a la caridad, si bien se trata de una actuación recomendada. El término, bastante genérico, se puede traducir como «benevolencia», y comparte el origen del tzedakah o zedaká judío. ${ }^{23}$ Incluye en su acepción todo tipo de concesiones voluntarias y espontáneas, destinadas a cualquier individuo, inclusive aquellos que no se encuentran sumidos en la pobreza o el sufrimiento. ${ }^{24} \mathrm{Al}$ igual que el zakät, constituye otra manera de expiar los pecados, junto a actividades como la liberación de esclavos y el ayuno. ${ }^{25}$

Por último, el waqf o hubs, ofrece la vía de la institucionalización de la caridad, tema de nuestro análisis, puesto que es el término hubs el que da origen al arabismo «habiz», mientras que waqf se emplea con mayor asiduidad en Oriente. ${ }^{26}$ En su sentido más básico, hablamos de «l'acte de fondation d'une institution charitable, d'ou l'institution elle-même». ${ }^{27}$ Más que de una tipología propiamente caritativa, se trata de una «cesión a perpetuidad del uso o usufructo de una propiedad con el fin de destinarlo en beneficio inmediato o futuro de alguna obra pía», en explicación muy precisa de Carballeira Debasa. ${ }^{28}$ Según Villanueva Rico, el hubs o habiss se puede traducir como «dedicado a un fin piadoso, consagrado o prometido a Dios». ${ }^{29}$

Como vimos, tanto las palabras waqf como hubs responden a una sola realidad -si bien compleja- que llamaremos de forma general «bienes habices», siguiendo la terminología presente en las fuentes castellanas. No obstante, debemos apuntar que existe otra multiplicidad de expresiones que designaron en momentos históricos determinadas fundaciones o legados píos/piadosos dentro del Islam, como la ya conocida șadaqa, muḥarrama, maḥbūsa, ḥubs mawqūfa o șadaqa mu'abbada, entre otras muchas. ${ }^{30}$ Se trata de una creación que ha perdurado en el Islam hasta

20. Vallvé Bermejo, Joaquín: Al-Andalus: sociedad e instituciones. Madrid, Real Academia de la Historia, 1999, p. 91.

21. Lev, Yaacov: «The Discourse of Charity and Piety in Medieval Arabic Literary Sources», en CARBALLEIRA DebASA, Ana María (dir.): Caridad y compasión en biografías islámicas. Madrid, CSIC, 2011, p. 73.

22. Maíllo Salgado, Felipe: Los arabismos del castellano en la Baja Edad Media. Consideraciones históricas y filológicas. Salamanca, Universidad de Salamanca, 1998, p. 415.

23. HoLmAN, Susan: «The language of social justice in early Christian homilies», en FrENKEL, Miriam y LEV, Yaacov (eds.): Charity and Giving in Monotheistic Religions. Berlín, Walter de Gruyter, 2009, p. 90.

24. FrenKel, Yehoshua: «Piety and Charity in Late Medieval Egypt and Syria», en idem, p. 189

25. Frenkel, Miriam; Lev, Yaacov (eds): op.cit., p. 9.

26. Carballeira Debasa, Ana María: «Aproximación a las donaciones piadosas en el Islam medieval: el caso de al-Andalus», en García LeAL, Alfonso (ed.): Las donaciones piadosas en el mundo medieval. Oviedo, Eujoa, 2012, p. 386.

27. HunWICK, John: «Wakf», en BeArman, Peri et.alii: op.cit., p. 65

28. Ibidem.

29. Villanueva Rico, María del Carmen: op.cit., p. 1.

30. Hennigan, Peter: The Birth of a Legal Institution. The Formation of the Waqf in Third-Century A.H. Hanafi Legal Discourse. Leiden, Brill, 2004, p. 50 
nuestros días, que dice remontarse a los tiempos de Mahoma, y que probablemente comenzó a partir del siglo I de la hégira, para adquirir una gran importancia a nivel socio-económico y jurídico ${ }^{31}$ a partir de los siglos Ill y IV del calendario islámico. ${ }^{32}$

García Sanjuán optó por describirlo a través de tres elementos: en primer lugar, considera que a nivel jurídico el habiz forma parte de «los actos espontáneos de la liberalidad del musulmán»; tras esto, incide en el fin piadoso del habiz, por lo cual debe seguir los preceptos del Islam y bajo ningún concepto ir en su contra, siendo los expertos en derecho islámico los que deben definir los marcos de la piedad; tanto Sanjuán como Carballeira consideran como parte esencial del habiz, su inalienabilidad e inalterabilidad, pues no se puede vender, ni traspasar y mucho menos destinar a una finalidad distinta de la que fue concebido. ${ }^{33}$

Bajo esta concepción, los waqf-s consisten en la entrega del uso o usufructo de parte o de la totalidad de los bienes privados de un individuo a un fin piadoso. Normalmente, los bienes que se cedían eran productivos, generadores de rentas, para a través de las mismas mantener al beneficiario o beneficiarios del habiz. ${ }^{34}$ Dentro de esta concepción tan amplia, encontramos toda una serie de diferentes bienes entregados, tanto muebles como inmuebles. El donador siempre debe corresponder al dueño de la misma. ${ }^{35}$ Los habices podían destinarse a una colectividad o a una sola persona. El donante debía de ser mayor de edad, y en la mayoría de ocasiones era hombre, aunque se conocen casos de mujeres fundadoras de un habiz. ${ }^{36}$ Pudiendo ser prácticamente cualquier persona un donante, el derecho mālikì impedía que fuera administrador de su propio habiz, por lo cual se solía nombrar un nāzir o administrador que velaba por el correcto uso del legado. Sobre este cargo nos encontramos al cadí, que tiene la capacidad de supervisar al nāziry tomar medidas ante cualquier irregularidad. ${ }^{37}$ Según recoge Trillo, la nominación del administrador dependía en buena medida del fundador del habiz, así como del propio cadí. ${ }^{38}$

Como afirma Carballeira, estos legados píos/piadosos podían hacerse en vida del fundador o a través del testamento. ${ }^{39}$ Dice la autora que era más común establecer los habices en vida, lo cual podríamos vincular al elevado prestigio social que suponía para un musulmán crear un legado de este tipo. Junto al reconocimiento,

31. Hennigan sitúa con cierta probabilidad la conversión del waqf en institución legal a partir del siglo III de la hégira, en tiempos de Ḥanafi. Idem, p. 187.

32. Carballeira Debasa, Ana María: Legados píos y fundaciones familiares en al-Ándalus (siglos IV/X-X-XII). Madrid, CSIC, Estudios Árabes e Islámicos: Monografías. 2, 2002, p. 23

33. Carballeira Debasa, Ana María: Legados píos..., p. 16 y García Sanjuán, Alejandro: Hasta que Dios herede la tierra. Los bienes habices en al-Andalus (siglos X-XV). Huelva, Universidad de Huelva, 2002, p.21-22.

34. Hernández Benito, Pedro: op.cit., p. 9.

35. Carballeira Debasa, Ana María: «Aproximación a las donaciones piadosas...», pp. 388-389.

36. García Sanjuán, Alejandro: op.cit., p. 102-105.

37. Hernández Benito, Pedro: op.cit., p. 33.

38. Trillo SAN JosÉ, Carmen: Agua, tierra y hombres en al-Andalus. La dimensión agrícola del mundo nazarí. Granada, Ajbar, 2004, p. 145

39. Carballeira Debasa, Ana María: «Aproximación a las donaciones piadosas...», pp. 388-389. 
debemos tener en cuenta el motivo último que empujaba al donador a realizar el legado pío/piadoso. Como vimos, el principal acicate del musulmán que realiza una obra piadosa o qurba es complacer a Dios, y a raíz de esa acción favorecer la salvación en el más allá. ${ }^{40}$ Sin embargo, hay casos en los que resulta evidente que hubo una finalidad mucho más mundana y material a la hora de la fundación. ${ }^{41}$ Así ocurre, por ejemplo, con las donaciones familiares (waqf ahlī) en las que se protege a un deudo, o se evita la fragmentación de la propiedad por la inalienabilidad del habiz, problema acentuado en la sociedad islámica por las estrictas leyes testamentarias.

Vemos que la familia es una receptora de habices, si bien lo más común era la entrega a otro tipo de destinatarios, colectivos en su mayoría. Muchos legados estaban dedicados a la manutención y construcción de edificios religiosos como las mezquitas, las rábitas, zāwiyas o casas de ablución, así como su restauración en caso de que fuera necesaria. Cuando se trata de habices dedicados a fines religiosos o de utilidad pública suelen denominarse waqf jayrī. ${ }^{42}$ Estos mismos, en el reino de Granada recibían en ocasiones el nombre de çobol alhayrat. ${ }^{43}$ Algunos gastos considerables de la mezquita derivaban del aceite para su iluminación, el salario del imām o la compra de esteras. Igualmente se han encontrado habices destinados al sostenimiento y levantamiento de cementerios. ${ }^{44}$ Recibían habices también los alfaquíes, para el pago de su salario; los pobres, los esclavos que debían ser manumitidos así como los cautivos a liberar. Dice Carballeira que, a diferencia de lo que ocurría en otros períodos históricos y ámbitos geográficos, en el reino nazarí se dedicaban también donaciones concretas a viajeros. Sin obviar aquellos habices dedicados a proteger a la comunidad en su sentido más básico: aportar armamento, caballos, fuentes, mantener muros, fortalezas, torres, etc. ${ }^{45}$ Este último punto resultaba crucial en una zona tan amenazada como el reino granadino, aunque el establecimiento de legados píos/piadosos para este fin es común en todo al-Ándalus. ${ }^{46}$ Trillo nombra asimismo, para el caso de la Alpujarra, habices dedicados al mantenimiento de las acequias, aljibes y puentes. ${ }^{47}$ Tampoco podemos olvidar los habices que financiaban hospitales, madrazas y la compra de libros para estas escuelas. Hernández Benito alude también al «pago del almotacén, pago del hạkim o juez de los delitos civiles». ${ }^{8}$ Con todo, la gama

40. García Sanjuán, Alejandro: op.cit. pp. 99-100.

41. Carballeira Debasa, Ana María: Legados píos y fundaciones familiares... p. 221.

42. Hernández Benito, Pedro: op.cit., p.32.

43. ESPINAR Moreno, Manuel: «Habices de la mezquita...», p. 53.

44. Carballeira Debasa, Ana María: «Aproximación a las donaciones piadosas...» pp. 397-398.

45. Idem, PP. 395-399.

46. Carballeira Debasa, Ana María: «Pauvreté et fondations pieuses dans la Grenade nașride: aspects sociaux et juridiques», Arabica, 52 (2005), p. 406.

47. Trillo SAN José, Carmen: La Alpujarra antes y después de la conquista castellana. Granada, Universidad de Granada, 1994, p.357.

48. Hernández Benito, Pedro: op.cit., p.32 
de destinatarios de legados píos/piadosos en el Islam medieval, y concretamente en al-Ándalus, era sumamente amplia, y nos remitimos a las extensas obras de Carballeira y Sanjuán para mayor detalle.

\section{LOS HABICES EN EL REINO DE GRANADA}

Para comprender mejor la génesis de los Libros de habices de principios del XVI, resulta inevitable acercarnos brevemente al convulso contexto que vivió Granada durante las últimas décadas medievales. Desde la formación del reino granadino en I238, se alternaron dos formas de convivencia con los reinos cristianos: la paz y la guerra, la tregua y el conflicto. La relativa tranquilidad de los períodos de tregua se intercala con frecuentes incursiones en territorio «enemigo» y una agitada vida de frontera durante las etapas de guerra. Esta alta inestabilidad afectará en buena medida el devenir del reino nazarí, que durante los siglos lidiará con conflictos internos y la pérdida de territorio.

Tras la Guerra de Sucesión castellana, que finaliza con la victoria de Isabel, junto a su marido Fernando de Aragón, comienza la etapa final del reino nazarí. La conquista de lo que era en aquel momento «el último reducto musulmán» de la península, se convierte en una prioridad para los nuevos monarcas. La Guerra de Granada, larga y con interrupciones asiduas, comienza con las primeras ofensivas exitosas para los castellanos en $\mathrm{I} 482$, con la toma de Alhama, en respuesta a la ocupación de la fortaleza cristiana de Zahara. ${ }^{49}$ Las capitulaciones de Granada, sin embargo, no llegaron a firmarse hasta el 25 de noviembre de I49I.

El texto suscrito por Boabdil, muy debatido en la historiografía, era benévolo con los vencidos. Al menos en la teoría, se respetaba su religión y se rechazaba la conversión forzosa. $5^{\circ}$ Podían ser juzgados por sus propias leyes y tribunales e incluso mantener sus propiedades, así como sus centros religiosos y costumbres, como la llamada del almuédano. ${ }^{5 \mathrm{I}} \mathrm{Al}$ igual que ocurre con otro tipo de propiedades de musulmanes, los habices son respetados en el texto granadino. Esto no era algo común en las capitulaciones más antiguas (Comares, Purchena, Almuñécar), pero sí había ocurrido ya en las de Almería. ${ }^{52}$ Así, se delega su administración en los alfaquíes, cargo difuso en cuanto a sus funciones, pero que se manifiesta estrechamente vinculada a las mezquitas..$^{53}$ Lo que sí parece claro es que el ejercicio

49. Malpica Cuello, Antonio, et.alii: Historia de Granada. Granada, Proyecto Sur, 1996, p. 96.

50. En la historiografía tradicional, la idea del respeto a la religión musulmana tras la conquista ha predominado. Si bien, recientemente se ha puesto en entredicho esta teoría para observar una dominación cristiana en las capitulaciones, así como una vía a la conversión. Véase: PoutRIN, Isabelle: «Los derechos de los vencidos: las capitulaciones de Granada (1491)», Sharq al-Andalus, 19 (2008-2010), pp. 11-34.

51. Una edición clásica de las capitulaciones la encontramos en: GARRIDo ATIEnZA, Miguel: Las capitulaciones para la entrega de Granada. Granada, Imprenta de Paulino Ventura Traveset, 1910.

52. García SanjuÁn, Alejandro: op.cit., p. 44.

53. Trillo SAN José, Carmen: «Agentes del estado y mezquitas en el reino nazarí», Historia. Instituciones. 
del alfaquí cambió notoriamente en el período de transición entre el reinado nazarí y el castellano..$^{54}$ En cierto modo, los habices se aseguraron al asignar a los alfaquíes para su cargo, pero la nueva élite dominante castellana, en un período de cuantiosas acciones de compra-ventas y posesión de nuevas tierras, debió de adueñarse ilegalmente de algunos bienes asociados a habices. 55 Otro factor a tener en cuenta es la despoblación que sufrió el Reino de Granada tras su conquista, especialmente por parte de aquellas personas con una economía suficiente para pasar al norte de África. Esto también pudo afectar a la correcta gestión y aprovechamiento de los habices durante los primeros años tras la toma de la capital

A pesar de todo, la situación cambia de forma abrupta tras I499, cuando tiene lugar la revuelta del Albayzín. Según Ladero Quesada, hubo algunos «chispazos de violencia» anteriores al conflicto de la capital, aún relacionados con el contexto de guerra..$^{6}$ Pero, como expone Carrasco García, desde el momento de la misma conquista hay tensiones entre los castellanos y granadinos que no cesan, aumentadas por los intentos proselitistas de los dominadores, la aparición de impuestos adicionales y una acuciante presión territorial..$^{57}$ La llegada de Francisco Jiménez de Cisneros a Granada y la conversión de los elches ${ }^{58}$ favorecerán en buena medida el rechazo de la población mudéjar, ya que para muchos los Reyes Católicos habían violado las capitulaciones, que, como vimos, rechazaban de pleno la conversión forzosa.59 Finalmente, el malestar de la población musulmana estalla el I8 de diciembre de 1499 en una revuelta de apenas tres días que, no obstante, invalidaba las capitulaciones y cambiaba, por lo tanto, todo el estatus socio-jurídico de la población granadina. Durante ese mismo mes, y continuando hasta el año I500, los reyes fuerzan al bautismo a numerosos musulmanes. ${ }^{60}$ Apenas dos años después, el día I2 de febrero de I502, los Reyes Católicos firman la Real Pragmática de conversión forzosa, que obliga a los mudéjares castellanos a elegir entre el bautismo o la expulsión. ${ }^{\text {[I }}$

Al desaparecer el estatus del mudéjar en el reino granadino, los habices pierden su sentido originario al no poder sostener ya ninguna estructura islámica. A partir de este momento pasan a la Corona de Castilla, que buscará su reparto: una parte

\footnotetext{
Documentos, 34 (2007), p. 285

54. Calero, María Isabel: «Muhammad al-Ŷayyār, un alfaquí a través de los manuscritos de Cútar», en ECHEvarRía ARsUAGA, Ana (ed.): Biografías mudéjares o la experiencia de ser minoría: biografías islámicas en la España cristiana. Madrid, CSIC, Estudios onomástico-biográficos de al-Andalus, XV, 2008, p. 401-402.

55. HeRnández Benito, Pedro: op.cit., p. 36.

56. LADERO Quesada, Miguel Ángel: «Mudéjares y repobladores en el Reino de Granada (1485-1501)», Cuadernos de Historia Moderna, 13 (1992), p. 54.

57. Carrasco García, Gonzalo: «Huellas de la sociedad musulmana granadina: la conversión del Albayzín (14991500)», En la España Medieval, 30 (2007), p. 338.

58. Minoría musulmana, suele denominarse así a los cristianos convertidos al Islam o descendiente de un cristiano converso. Idem, p. 362

59. Coleman, David: Creating Christian Granada: Society and Religious Culture in an Old-World Frontier City, 14921600. London, Cornell University Press, 2003, p. 38

6o. Carrasco García, Gonzalo: op.cit., p.338.

61. En Aragón, Fernando permite su presencia hasta 1515. Coleman, David: op.cit., pp. 6-7.
} 
derivará en mercedes, otra parte irá al cabildo y a la Iglesia granadina, mientras el resto permanecerá en sus propias arcas. ${ }^{62}$ Para poder llevar a cabo la redistribución de estos habices se hizo evidente la necesidad de conocer los bienes, su ubicación y valor, de gran número y complejidad. ${ }^{63}$ La necesidad de registrar con detalle estas rentas y propiedades es la causa última de que se conserven hoy los habices granadinos, multiplicados por los pleitos que hubo durante la Edad Moderna. ${ }^{64}$

\section{LA ALQUERÍA DE LA ZUBIA A TRAVÉS DE LOS HABICES}

\subsection{LA ALQUERÍA}

Al sur de la ciudad de Granada se encuentra la actual localidad y municipio de La Zubia, asentada sobre una antigua población de origen árabe. Si bien es cierto que se han encontrado registros arqueológicos de períodos tan tempranos como la Edad de Bronce en cuevas cercanas a la población, como el caso de las Cuevas del Moro, de la Paloma o de la Vieja. ${ }^{65}$ Otros yacimientos sacaron a relucir restos de período romano, asociado a villas, que hacen cuestionar el asentamiento anterior a la invasión islámica. ${ }^{66}$

El topónimo puede derivar de al-Zāwiya, que según Jiménez Mata significa «alquería de la ermita». Vidal Castro, por su parte, cree que «zubia» puede derivar de al-zubya: «sitio donde se reúne mucha agua o por donde corre». ${ }^{67}$ Las primeras referencias a su nombre se encuentran en el siglo XIII; no obstante, al identificarse como iqlìm en Ibn al-Zubayr, algunos consideran que se puede remontar al siglo VIII ${ }^{68}$ y a las primeras divisiones administrativas de origen árabe en la región granadina. Este autor afirma que al distrito de al-Zāwiya pertenecían las alquerías de «Qulŷar (Gójar), Yāŷar al-sāmiyyīn, Yâŷar al-baladiyyīn, Uŷiŷar y Qaștāla» ${ }^{69}$. Pero, como bien apunta Carvajal López, se trata de una zona extremadamente urbanizada, que hoy por hoy impide conocer bien el origen del asentamiento. ${ }^{\circ}$

62. Hernández Benito, Pedro:, op.cit., p. 36

63. Álvarez de Morales, Camilo: «Romanced Documents, Bilingual Documents and Books of habices», en SIJPESTEIJN, Petra et.alli (eds.): Islamic History and Civilization: From Al-Andalus to Khurasan: Documents from the Medieval Muslim World. Tomo 1, Leiden, Brill, 2007, p. 4.

64. Villanueva Rico, María del Carmen: op.cit., p. 4.

65. Ayuntamiento de La Zubia: Catálogo de Bienes y Espacios Protegidos, 2014, pp. 16-18.

66. Idem, pp. 19 y 37.

67. Vidal CAStro, Francisco: «El agua y los arabismos en español. Relación de los principales vocablos», en Castillo Castillo, Concepción et.al. (coord.): Homenaje al profesor José María Fórneas Besteiro. Universidad de Granada, Granada, 1995, p. 543

68. JimÉnEz MATA, María Carmen: La Granada islámica. Contribución a su estudio geográfico-político-administrativo a través de la toponimia. Granada, Universidad de Granada, 1987, p. 696.

69. Ibidem.

70. Carvajal López, José Cristóbal: La cerámica de Madinat Ilbira (Atarfe) y el poblamiento altomedieval de la Vega 
No obstante, podemos estar seguros de que la alquería existió en los siglos XIII, XIV y XV sin interrupción, pues es citada, entre otras fuentes, en la conocida lista de Ibn al-Jatib como qarya en su Ihäta.$^{7 \mathrm{I}}$

Existen relativamente pocos datos sobre cómo podía ser esta alquería antes de la conquista castellana, si bien sabemos que el paraje en el que se encontraba formaba parte de la fértil Vega de Granada, con unos sistemas complejos de irrigación que debieron de propiciar los cultivos de huerta y, a modo general, un intenso aprovechamiento agrario del terreno. Destacan algunas acequias que toman sus aguas del río Monachil, como la Acequia Gorda, llamada en numerosos casos acequia de La Zubia, o la acequia del Genital, que a su vez da nombre a un pago del término poblacional..$^{2}$ En esta localidad, los sistemas de riego e incluso sus turnos dieron nombres a otros pagos y crearon una vinculación histórica con pueblos cercanos como Cájar y Monachil. ${ }^{33}$ Algunos tramos de las acequias árabes aún se conservan junto a sus arcos, que en numerosos puntos requieren una mayor intervención arqueológica para su preservación y para desentrañar la conexión con los Baños Árabes y la Alberca Grande que se encuentran en la localidad, fechadas aún de manera imprecisa. ${ }^{74}$

Asimismo tenemos constancia de que en el territorio que rodea La Zubia existe un gran número de propiedades de tipo aristocrático, como almunias de la familia real nazarí, tema estudiado recientemente por Carmen Trillo.75 Merece la pena citar la almunia de Dar Nublo, investigada por esta misma autora ${ }^{76}$, Darabenaz de la que aún se conservan restos en la actual Casa de la Marquesa, o algunos nombres que serán objeto de interés, como Daralcohayle y Daralgazi. Estas fincas tendrían una doble funcionalidad, al servir tanto de centro de explotación agraria como de lugar de recreo para la élite, que podía deleitarse en los jardines, estanques y palacetes que formaban el complejo de la almunia. Un breve fragmento literario que recoge al-Maqqarī en su Nafh al-țīb nos da la imagen, idílica y ensalzada, de un maŷlis o «reunión báquico-literaria» ${ }^{77}$ que, supuestamente, tuvo lugar en La Zubia:

«Bebió un día Ibn Nizār con Abū Ŷa'far ibn Sa'ìd y el poeta al-Kutandī, en un jardín de la Zubia de Granada. En él había un estanque (șihrîy) de agua rodeado

de Granada. Granada, Arqueología y Cerámica, Grupo de Investigación Toponimia, Historia y Arqueología del Reino de Granada, 2008, p. 175.

71. JimÉnez MATA, María Carmen: op.cit., p. 697.

72. Sobre los repartimientos del agua en esta zona véase: Espinar Moreno, Manuel. «Consideraciones sobre el regadío en la Vega de Granada. Repartimientos musulmanes (siglos XII-XVI)», Chronica Nova, 18 (1990), p. 121-153.

73. Castillo Ruiz, José, Martínez Hidalgo, Celia y Pérez Córdoba,Gloria: «El sistema histórico de riego de la Vega de Granada. Reconocimiento y protección desde la perspectiva del Patrimonio Agrario», en SANCHIS-IBOR, Carles; et al. (eds.): Irrigation, Society and Landscape. Tribute to Thomas F. Glick. Universidad Politécnica de Valencia, Valencia, 2014, p. 777

74. Ayuntamiento de La Zubia: op.cit., p. 33

75. TRILlo SAN JOSÉ, Carmen: «Propiedad aristocrática en el reino nazarí de Granada (siglos XIII-XV): almunias versus alquerías» [En prensa]

76. Trillo SAn José, Carmen: «El Nublo, una propiedad de los infantes de Granada», Homenaje al profesor José María Fórneas Besteiro. Vol. 2, 1995, pp. 867-879.

77. MoraL, Celia del: «Jardines y fuentes en al-Andalus a, través de la poesía», MEAH, 58 (2009), p. 246. 
de naranjos, limoneros y otros árboles. Sobre él había un surtidor de agua que movía la imagen de una muchacha (ŷāriyya) danzando entre los chorros, y un plato de mármol (tayfur rujām) que formaba en la conducción del agua la imagen de una tienda. ${ }^{78}$

Otras noticias sobre la alquería nos llegan gracias al episodio, convertido ya en mito, en el que la reina Isabel, queriendo ver la ciudad de Granada, se acerca a La Zubia para mirarla desde lejos. Tanto Bernáldez como Hernando del Pulgar ${ }^{79}$ concuerdan en que Isabel contempló las vistas desde una casa de dicha localidad, y Bernáldez añade que se trataba de una «casa muy buena» ${ }^{80}$, pudiendo tratarse de una vivienda aristocrática. Según cuentan algunas versiones, tuvo lugar una batalla que obligó a la reina a esconderse en un bosque de laureles, donde rezó a San Luis para la victoria de sus soldados. Al vencer, ya tras la conquista, se erige en este lugar el Convento de San Luis El Real. Un cronista muy tardío, Alonso de Torres, describe la alquería en estos términos:

«Y deseosa de ver los hermosos edificios, y dilatada habitación de los Moros Granadinos, determinó ir con algunos Soldados a la Zubia, Villa, distante una legua de la populosa Ciudad, azia la falda de la Sierra Neuada, cuya situación es entre tantas fuentes, huertas, árboles, y azequias, que siendo población de trecientos vezinos, mas parece un campo adornado de muchas casas de recreo, pues cada qual tiene su dilatada huerta. ${ }^{81}$

Nos han llegado referencias incompletas y dudosas sobre un pequeño palacete situado enfrente de estos célebres laureles que, según la información que recogió Marín Fernández, perteneció a un árabe pudiente vinculado a la familia de Cetti Merien. Según este erudito local, el edificio con sus huertas pasaría luego al arzobispo de Granada, Gaspar Ávalos de la Cueva, conociéndose esta hacienda como El Jardín. ${ }^{82}$ El mismo autor nos habla sobre otras casas señoriales de La Zubia, que por los restos pudieron remontarse a período islámico, como una situada frente al callejón del barrio Molino, y de una huerta, que según él perteneció a los monarcas nazaríes, llamada Huerta Grande. ${ }^{83}$

El carácter de iqlīm y la correspondiente adscripción de varias alquerías nos puede dar la imagen de cierta preponderancia de La Zubia sobre los territorios de su alrededor. Este predominio parece persistir en el tiempo puesto que en I504, y

78. Idem, p. 247.

79. Pulgar, Hernando del: Crónica de los señores Reyes Católicos Don Fernando y Doña Isabel de Castilla y de Aragón. Valencia, Imprenta de Benito Monfort, 1780, p. 374.

8o. Bernáldez, Andrés: Historia de los Reyes Católicos Don Fernando y Doña Isabel. Sevilla, Imprenta que fue de J.M Geofrin, 1869, p. 296.

81. TORRes, Alonso de: Chronica de la Santa Provincia de Granada, de la regular observancia de N. Serafico Padre San Francisco. Madrid, Impresor Juan García Infançon, 1683, p. 106.

82. Marín Fernández fue un erudito local cuyos estudios fueron publicados de forma póstuma, no podemos saber con exactitud de donde proceden los datos que cita pues no hace referencia a las fuentes. Se trata de una información con la que debemos ser cautelosos, pero no es carente de interés. MARín FERnÁNDEZ, José: Historia de La Zubia de José Marín. La Zubia, Asprogrades, 2013, p. 112.

83. Idem, pp. 233-235 у 272. 
durante los primeros años tras la conquista castellana, se registran elevados niveles de densidad demográfica, contabilizándose unos 204 vecinos. ${ }^{84}$ Esta población también se nos muestra, entre las alquerías más pudientes y habitadas, en las alcabalas y diezmos estudiados por Hernández Benito a partir de documentación entre los años I5OI y $1506 .{ }^{85}$ Las huellas que apuntan a un elevado número de propiedades reales y aristocráticas en el lugar, también nos invitan a pensar en una alquería marcada por la riqueza agraria y las construcciones palaciegas durante el ocaso del reino nazarí. Las edificaciones de tipología religiosa debieron de abundar en La Zubia bajo dominio islámico, como parece indicar al menos uno de los posibles orígenes del topónimo y los restos de zāwiyas excavados en su cercanía. ${ }^{86}$

\subsection{BIENES DE LA ZUBIA EN LOS HABICES DE 1503 Y 1505}

Expondremos a continuación algunas cifras de interés obtenidas a través de nuestro análisis de los habices mencionados. En primer lugar, debemos hacer referencia a la información genérica, si bien cabe recordar que trabajamos con datos imprecisos, puesto que algunas entradas no especifican marjales y síla renta, y otros mencionan su extensión pero no su valor. Por ello, se trata de datos complejos que debemos manejar con precaución y asumiendo que exponen una realidad parcial.

En los habices de 1503 se encuentra un total de 199,5 marjales arrendados en La Zubia, distribuidos en 63 entradas, que de forma general corresponden a un haza mencionado en la fuente. Su valor total es de I2.044 maravedís de renta anual, equivaliendo a 60,3 $\mathrm{mrs} / \mathrm{mrj}$ de renta y I9I,I maravedís por entrada o haza del habiz. La extensión media de cada haza o entrada es de 3,I6 marjales. Corresponden tanto a habices de alquería, de cautivos, la escuela de los Axares y la gima Chinteyr. ${ }^{87}$

En los habices de 1505 contamos con un total de 107 entradas pertenecientes a La Zubia, que forman 380 marjales con un valor total de 22.745 maravedís de renta anual, lo que son unos 59,85 mrs/mrj y 212,5 maravedís por entrada o haza. Aquí, la extensión media es de 3,55 marjales. Vemos que entre ambos habices, el valor del marjal no se ve apenas trastocado, y tampoco se altera mucho la suma obtenida del valor de las hazas, si bien vale un tanto más en los de 1505 y son ligeramente más extensas. De estos 380 marjales, un 19,34\% corresponde a las hazas

84. Galán Sánchez, Ángel y Peinado Santaella, Rafael: Hacienda regia y población en el Reino de Granada: la geografía morisca comienzos del siglo XVI. Granada, Universidad de Granada, 1997, p. 112.

85. Véase: Hernández Benito, Pedro: «Alcabalas y diezmos. Economía y estructura del poblamiento en la Vega de Granada a través de las fuentes fiscales castellanas (1501-1506)», Arqueología y territorio medieval, 3 (1996), p. 65-90.

86. Álvarez García, José Javier y García Porras, Alberto: «La zawiya del Cobertizo Viejo (Granada)», Anuario Arqueológico de Andalucía. Sevilla, Junta de Andalucía, 2003.

87. Los datos extraídos del habiz de 1503 parten desde luego del libro de Hernández Benito, mientras que los del habiz de 1505 pertenecen a la recopilación de Villanueva Rico. 
de la alquería de La Zubia, un 5,78\% a la rábita de Harat Alhazem, un 6,05\% a la rábita de Haratanza, un II,05\% a la rábita de Harat Adarap, un 9,47\% a la rábita de Alnex y un 48,28\% a habices no pertenecientes a la propia Zubia, como las Heredades de Santa María de la O, la rábita de Hilila, la rábita de Vin Alvira o alquerías como Cénex, Monachil, Güetor y Ugíjar (Los Ogíjares).

En conjunto, hay 579,5 marjales que pertenecen a La Zubia, cuyo valor total asciende a 34.789 maravedíes de renta. Estos marjales se encuentran distribuidos en un total de I70 entradas, con lo cual obtendremos un 60,03 mrs/mjl y 204,64 maravedís por entrada. La media de extensión conjunta es de 3,4 marjales por entrada o haza. Esta información resulta de especial interés puesto que nos permite ver que los arrendamientos que se producen bajo los habices durante este período de tiempo son de extensión más bien moderada, lo cual encaja con la información que tenemos de otras áreas periurbanas de la ciudad de Granada durante esta misma época. ${ }^{88}$ No obstante, no podemos ignorar que la media se ve disminuida por las hazas que no hablan de su extensión y las de un solo marjal, cuando existen al menos nueve arrendamientos que superan o igualan los Io marjales, siendo el mayor de los mismos el que tiene Luiz Almojeiref en el pago de Duchi Ramizal, de 15 marjales.

\begin{tabular}{|c|c|c|c|c|}
\hline \multicolumn{5}{|c|}{ VALORES TOTALES } \\
\hline Tablas & $\begin{array}{l}\text { Número de } \\
\text { entradas }\end{array}$ & Marjales & $\begin{array}{l}\text { Promedios (marjales } \\
\text { por entrada) }\end{array}$ & Sumas \\
\hline $\begin{array}{l}\text { Habices de la alquería } \\
\text { de La Zubia } 1503\end{array}$ & 63 & 199,5 & 3,16 & $\begin{array}{l}375 \text { pesantes; } \\
9 \text { dineros; } 23 \text { reales }\end{array}$ \\
\hline $\begin{array}{l}\text { Hazas de la alquería } \\
\text { de La Zubia }\end{array}$ & 25 & 73,5 & 2,94 & \multirow{5}{*}{$\begin{array}{l}13712,5 \text { maravedís (sin } \\
\text { habices de mezquinos) }\end{array}$} \\
\hline $\begin{array}{l}\text { Rábita de Harat } \\
\text { Alhazem }\end{array}$ & 11 & 22 & 2 & \\
\hline Rábita de Haratanza & 9 & 23 & 2,55 & \\
\hline $\begin{array}{l}\text { Rábita de Harata } \\
\text { Adarap }\end{array}$ & 7 & 42 & 6 & \\
\hline Rábita de Alnex & 12 & 36 & 3 & \\
\hline $\begin{array}{l}\text { Hazas de La Zubia } \\
\text { pertenecientes a } \\
\text { otros habices } 1505\end{array}$ & 43 & 183,5 & 4,26 & $\begin{array}{l}8812 \text { maravedís; } \\
6,5 \text { reales }\end{array}$ \\
\hline Total & 170 & $\begin{array}{c}579,5 \\
\text { marjales }\end{array}$ & 3,4 & $\begin{array}{l}22524,5 \text { maravedís; } \\
29,5 \text { reales; } 375 \\
\text { pesantes; } 9 \text { dineros }\end{array}$ \\
\hline
\end{tabular}

88. Trillo SAN JosÉ, Carmen: «El tiempo del agua. El regadío y su organización en la Granada islámica», Acta historicaet archaeologica mediaevalia, 23-24, (2002), pp. 237-286. 


\subsection{CULTIVOS Y FORMAS DE EXPLOTACIÓN}

Recordemos que los cambios de propiedad y explotación que sufrió esta parte de la Vega de Granada, cercana a la capital, tuvieron que ser ligeramente distintos a la región más occidental, puesto que en aquellos territorios conquistados previamente a la firma de las capitulaciones los mudéjares pierden sus bienes. ${ }^{89}$ Aún así, los cambios debieron acelerarse también aquí en los primeros años tras la conquista, gracias a los ya citados procesos de compra-venta entre los que pasaron allende y los recién llegados, permitiendo la consolidación de una nueva élite castellana.

A diferencia de lo que ocurre en los habices de otras alquerías granadinas como Cénex, Quéntar o Dúder ${ }^{\circ \circ}$, en el caso de La Zubia son muy precarios los datos que tenemos sobre los tipos de cultivos y las formas de explotación del territorio. Ni en la documentación de 1503 ni en la de 1505 es común encontrarse referencia alguna a especies plantadas, o si la tierra es de regadío o de secano. Sin embargo, resulta verosímil pensar que la mayor parte de los bienes citados corresponde a cultivos de regadío, teniendo en cuenta la extensa red de acequias que existía, y todavía existe, en esta zona de la Vega. La huerta de regadío permitía elevados niveles de productividad en la obtención de hortalizas y frutales durante el dominio nazarí. Como apunta Hernández Benito, estas huertas se solían situar en el interior de las alquerías o muy cerca de las mismas, aprovechando el curso de acequias y ríos. ${ }^{91}$

Por otro lado, debemos tener en cuenta que en 1570 hay una notoria abundancia de trigo en la zona, pero también cebada, habas, tierra olivar, algo de centeno y tierras calmas ${ }^{92}$, por lo que no podemos desechar que abundaran también estos cultivos en un período anterior. Si bien es cierto que existe un marcado consenso en afirmar que disminuyeron especies de legumbres y frutales a favor de cultivos más apetecibles para la sociedad castellana como los cereales, el olivo y la vid. ${ }^{93}$ Es por ello que resulta tan dificultoso conocer la proporcionalidad de cultivos de un período anterior a la conquista.

Encontramos dos excepciones en los habices de La Zubia, que nos hablan de especies concretas y su ubicación. La primera en la mención de dos morales en la tierra arrendada por Almahaluf, vecino de La Zubia, en el pago de Andaralafrán. La segunda, y más relevante, en la referencia a las viñas que podemos encontrar en esta población, presente en los habices de 1505. La información es escasa,

89. Hernández Benito, Pedro: La Vega de Granada...p. 84

90. Es frecuente encontrarse en los habices de estas alquerías, amplias alusiones sobre las fanegas de cereal cultivado y el nombramiento de especies arbóreas como alcornoques, almendros, nogales, etc. Villanueva Rico, María del Carmen: op.cit., pp. 225-238.

91. Hernández Benito, Pedro: La Vega de Granada...p. 87.

92. EsPInAR Moreno, Manuel: Libro de Apeo de la Zubia en 1570. Estudio y transcripción. Granada, Libros EPCCM, 2015, pp. 19-22.

93. Hernández Benito, Pedro: La Vega de Granada...p. 87 
puesto que solo se cita la extensión de la viña en dos casos (una de i marjal, otra de 4 marjales). Vemos que la ubicación coincide en dos casos: se encuentran en un pago llamado Corbales o Cornales, que hemos podido encontrar, pues aún se conserva un cortijo y ramal de acequia ${ }^{94}$ del mismo nombre al sureste del núcleo principal. Otro lugar que se nombra es el «Goros de las viñas», mas no tenemos mayor información sobre éste aunque podría equivaler al topónimo «Algoroz» que también se encuentra en la alquería, dando nombre a un pago y acequia en el Apeo de 1570.95

\subsection{CONSTRUCCIONES Y VÍAS DE COMUNICACIÓN}

Como hemos podido ver con anterioridad, la población de La Zubia era densa y abundante en el tránsito del dominio nazarí al castellano, por lo que debieron proliferar las viviendas familiares en esta zona, sin hablar ya de las posibles almunias. En los habices se citan únicamente cinco casas pertenecientes a la alquería en $\mathrm{I505}$, lo cual nos hace comprender que la mayoría de viviendas no correspondían a ningún habiz conocido, sino que formaban parte de manos privadas. En una única entrada se hace referencia a lo que debió ser el núcleo residencial de La Zubia, al hablar de un haza «junto con las casas».

Entre otros elementos constructivos que nombra el habiz destaca un horno ${ }^{96}$, linde de una propiedad del anciano Gerónimo Abdurrazic (Abdurrasic, Abdurraçic), figura que se menciona en reiteradas ocasiones en ambos documentos. De forma más sutil, se hace alusión a la existencia de una almadraba, probablemente para la fábrica de tejas y ladrillos. Con cierta seguridad, esta misma almadraba dio nombre a un pago: «Un haza en la Zubia que es de la dicha Santa María de la O, que la tenía Abentercatre en el Almadrava, alinde la Almadrava...».97 No podemos descartar que ésta responda a la misma de Ugíjar (Ogíjares), población vecina, y que haya cierta confusión entre los límites de ambas localidades. Vemos que en el Apeo de I570 hay varias almadrabas en la población y que además persiste el topónimo. Este pago debió de situarse cerca de la acequia principal, al lado del camino que va desde Ogíjares a Granada y la casa de Modarra ${ }^{98}$, presumiblemente el actual cortijo llamado Casa de Moharra. Hoy persiste un pago denominado «Compuerta del Horno», en una ubicación muy semejante a la que nos da el Apeo, aunque puede aludir a un horno de pan.

94. Nos referimos al Cortijo de Corvales y al ramal de acequia de Barranco de los Corvales

95. Espinar Moreno, Manuel: Libro de Apeo de la Zubia..., p. 39.

96. Villanueva Rico, María del Carmen: op.cit., p.266.

97. Idem, p. 70

98. Espinar Moreno, Manuel: Libro de Apeo de la Zubia..., p. 138. 
En cuanto a los elementos viarios que citan los habices, podemos destacar dos caminos principales: el primero de ellos es el que lleva desde La Zubia hasta la capital, y el segundo el que se dirige hacia el pago de Yéjar (también Yáxar), que es el más nombrado. Otros se citan sin alusión a su destino, como el que pasa al lado de un haza de Baroma, otro que linda con tierras de Jafar, uno al lado del pago de Balat Arrahal o el que linda con Botorni. También se cita una senda que linda con Fernando Aviz el Rumayli. Aunque no sean mayores las alusiones a vías, podemos suponer que La Zubia contaba con una comunicación interna suficiente, y bastante buena con la cercana ciudad de Granada.

\subsection{PAGOS REGISTRADOS}

Los habices relativos a La Zubia recogen un total de 20 nombres de pagos:

Abruchil: No se encuentra en el Apeo de 1570 ni en ninguna otra fuente conocida. Ubicación incierta.

Almadrava: Como apuntamos anteriormente, se encuentra con alta probabilidad en el límite entre Ogíjares y La Zubia, cerca del camino que se dirige a Granada.

Andaralafrán: Pocklington traduce este topónimo por la «era de los hornos», al considerar «afrán» como «hornazas u hornos de cocer pan». ${ }^{99}$ ¿Podríamos vincular también este pago con la actual «Compuerta del Horno»? Vemos que las tierras citadas en Andaralafrán corresponden a un único dueño. Topónimo inexistente en el Apeo de I570.

Balat Arrahal: Pago citado en ambos habices, recuerda al Balata Alarrac del Apeo, pero probablemente éste corresponda antes al Pago de Buenti Alaarax.

Buenti Alaarax, Fadín Alcazbor, Yéjar, Aben Fite (cercanos entre sí): El pago de Fadin Alcazbor se puede registrar aún en el Apeo, con una extensión de 100,5 marjales, bajo ese mismo nombre o como Fadín Alcazuar/Alcazuor. ${ }^{100}$ Debió de encontrarse relativamente cerca del término de La Zubia con Cájar, lo cual nos da una idea general sobre la ubicación de los otros pagos. Buenti Alaarax debe de corresponder al pago del Apeo, denominado «Pago de Balata Alarrac» y «Pago de Balata Alarrax», que toma el agua de la Acequia Grande el martes «desde el lucero hasta el medio día». ${ }^{\text {ror }}$ Sobre Aben Fite no tenemos información, si bien debe de estar cerca de los pagos anteriores. Sobre Yéjar (o Yájar), en cambio, debemos añadir varias observaciones. Se trata de un pago importante en los habices de La Zubia, bordeado por un camino que lleva su nombre. Algunos autores se han hecho eco de la semejanza del topónimo de las alquerías Yâŷar al-Baladiyyīn

99. Pocklington, Robert, «Lexemas toponímicos andalusíes», Alhadra. Revista de la Cultura Andalusí, 2 (2016), p. 237. 100. Idem, p. 19.

101. Espinar Moreno, Manuel: Libro de Apeo de la Zubia..., p. 32 y 61. 
y Yāŷar al-Šāmiyyīn de las que habla Ibn al-Jatib, aludiendo a una diferenciación entre baladíes y sirios en el asentamiento. ${ }^{102}$ Quedan algunos restos de una construcción conocida como Torreón de Yéjar, pero no existen estudios profundos sobre esta supuesta población.

Dar Halja / Dar Halja Coronilla: No se encuentra en el Apeo. El pago incluye el término «dar», empleado asiduamente para hacer referencia a construcciones aristocráticas, aunque puede aludir a una casa normal.

Fadín Açeca: En el Apeo de 1570 sigue mencionándose bajo el mismo nombre un pago de 89 marjales, cerca de Cájar. ${ }^{\mathrm{IO3}}$

Fadín Alachop, Fadín Aseytuna, Fadín Fas/Alfas, Fadín Alaydal, Fadín Almaresten: No hay datos referentes a estos cinco pagos, si bien el segundo de ellos nos da información sobre un posible cultivo de olivos.

Hauz de Hajar: Pocklington apunta al significado de Hauz de Hajar como «distrito de la peña». ${ }^{104}$ En el Apeo persisten formas como Axar/Ajar/Haxar, y linda directamente con Cájar. ${ }^{105}$

Pago de Corbales/Cornales: Como dijimos, se encuentra al sureste de La Zubia, con vestigios del topónimo en una acequia y cortijo del mismo nombre. Destaca por la presencia de viñas.

Pago de Mahajar Alcavala: No hemos encontrado su ubicación ni un equivalente exacto en el Apeo, pero es evidente que el pago está atravesado por el camino a Granada. Los pagos que más recuerdan al topónimo son los de Majaral o Mazarrahea.

Pago de Quinicia: Sin información sobre su localización en La Zubia. Seco de Lucena hace referencia a un pago del mismo nombre en el término municipal de Albolote. ${ }^{\text {106 }}$

Pago del Romizal: Este pago es de los pocos que podemos encontrar representado aún en mapas actuales, puesto que existe hoy un Pago del Romizal en la actual Ogíjares, cerca de Armilla. También presenta la forma intermedia en el Apeo, como Romiçal.

\subsection{LOS VECINOS DE LA ZUBIA}

La rica información que ofrecen los habices se plasma también en los datos toponímicos y onomásticos. Esto permite acceder a gran número de nombres de persona y sus diversas ramas familiares, que habitaron La Zubia entre finales del siglo XV y comienzos del XVI, y conocer al menos parcialmente su estatus

102. Martínez VÁzquez, Luis: La Vega de Granada. Transformaciones y cambio de los paisajes entre el Reino Nazarí y el Reino de Granada. Granada, Universidad de Granada, 2015, p. 248.

103. Espinar Moreno, Manuel: Libro de Apeo de la Zubia..., p. 19.

104. POCKLINGTON, Robert: op.cit., p. 257.

105. Espinar Moreno, Manuel: Libro de Apeo de la Zubia..., p. 176.

106. Seco de LucenA, Luis, «Toponimia árabe de la Vega y los Montes de Granada», Al Andalus, 29, (1964), p. 325 
económico. Es común encontrar muchos de los nombres de los habices de 1503 en el Libro de 1505, e incluso en el Apeo, tratándose con elevada probabilidad de descendientes de los mismos. También podemos rastrear algunas de las familias residentes en Ugíjar (Ogíjares) cuyos vecinos tenían propiedades en La Zubia por su proximidad, o aquellos que se trasladaron a esta alquería desde otras cercanas como Monachil, conservando en su nombre la referencia toponímica. Junto a denominaciones como Monachili, veremos que otras proceden de lugares más alejados como Guadixi (Guadix) o Almalaqui (Málaga).

Entre los individuos con más terrenos en la región podemos citar al viejo Abdurraçic, del que ya hablamos, o a Juan el Carmoní, un cristiano viejo que aparece como propietario de múltiples tierras de habices y cuantiosos linderos. Cabe preguntarse sobre el origen de la adquisición y acumulación de sus bienes en esta zona, y en qué momento se produjo. Es el único cristiano viejo que se cita como tal y con nombre completo, y al mismo tiempo uno de los mayores propietarios. En el Apeo de 1570 encontramos al menos cuatro hombres que comparten su nombre, tres de ellos viven en La Zubia y uno en Los Ogíjares, por lo cual podemos suponer que el asentamiento de esta familia en la región fue un éxito prolongado. De hecho, Lorenço Carmoni, vecino de «Ugíjar la Baxa», figura como uno de los testigos del Apeo. ${ }^{\mathrm{I} 7}$

Destaca también Barona o Varona, cuyo nombre no se cita de forma completa en la mayoría de los casos, por lo cual no sabemos si se trata de Lorenzo Mahamed Barona o Fernando Hamete Barona, o si incluso hablamos de toda una familia de cierta influencia en la región. Un Andrés Barona y sus hermanos aparecen en el Apeo como «revelados» ${ }^{108}$, mientras otros Barona se citan pero no bajo tal calificativo, por lo cual es muy posible que se trate de una familia con ramificaciones más extensas.

Entre los nombres que más llamaron nuestra atención están los de Gazi, Gasi o Algazi, no solo comunes en estas fuentes sino que también se podrían vincular a una de las grandes construcciones que se encontraba en las inmediaciones de La Zubia. Hablamos del heredamiento de Daralgazi, cedido en 1504 a don Sancho de Castilla por los Reyes Católicos. ${ }^{109}$ Anteriormente había formado parte del patrimonio de la familia real nazarí, pasando a los monarcas castellanos durante las negociaciones de Hernando de Zafra con Boabdil. ${ }^{\text {II }}$ Los Gazi debían de pertenecer a un estrato socio-económico al menos medio-alto, por los bienes que poseen en la localidad así como por el registro de uno de sus miembros, Gonzalo el Gazi, como mayordomo del cortijo de Láchar bajo Álvaro de Luna, hasta su traspaso en

107. Espinar Moreno, Manuel: Libro de Apeo de la Zubia..., p. 87.

108. Idem, p. 154.

109. AGS, CCA, CED, 1, 39, 2: «Merced a don Sancho de Castilla de la casa de Daralgazí en Granada».

110. Salvá, Miguel y Sainz de Baranda, Pedro: Colección de documentos inéditos para la Historia de España. Tomo XI. Madrid, Imprenta de la viuda de Calera, 1847, p. 543-544. 
I5I2. ${ }^{\text {III }}$ En el Apeo veremos que se perpetúa el antropónimo con Alonso el Gazi y su tío del mismo nombre, vecinos de La Zubia. Otro varón, llamado Luis Hernández el Gazi, figura entre los que debieron declarar sobre el uso y posesión de las aguas de La Zubia. ${ }^{\mathrm{II2}}$ Desconocemos el grado de parentesco entre estas personas y los Gazi que participaron en la sublevación, entre ellos Francisco el Gazi, vecino de Monachil y Alonso el Gazi, del mismo lugar. Se trata sin duda de un nombre ligado a figuras de cierta notoriedad que se ubican en la zona sur de Granada, dispersados entre las alquerías de La Zubia, Los Ogíjares y Monachil.

Otros apellidos se repiten, de forma exacta o semejante, en los Libros de habices vinculados a La Zubia y el Apeo:

Aben Baca/Abenbaca; Talha: Tanto en los habices como en el Apeo se trata de vecinos de Los Ogíjares.

Abenzali/Abençali: Vecino de Ugíjar en los habices, en el Apeo aparece un vecino de Granada y otro de «Ugíjar la Baja» que comparten la denominación.

Abenzilin/Abençeli/Bençeli: Vecino de Ugíjar en los habices, en el Apeo encontramos dos hombres, uno de La Zubia y otro de «Ugíjar la Baja».

Alazeraque; Almonahal/Almohanahar/Monahal/Monahar; Çana/Zana/Zanas; Haron; Reduan: Corresponden en ambos documentos a vecinos de La Zubia.

Alcaijon/el Cayxon: Alcaijon se nombra entre las lindes de los habices, mientras «el Cayxon» da nombre a dos vecinos de «Ugíjar la Alta» en el Apeo.

Alixbili/Lisbili: Citado como «alguasil» en los habices. El nombre pudo derivar en los «Lisbili» del Apeo, también vecinos de La Zubia.

Çayde/Zayde/Abençayde: En los habices de 1503 se cita a Alvaro Çayde Algazi, vecino de La Zubia. En el Apeo aparece Martín Carrillo Zayde y sus hijos -el único hijo varón fue un «revelado»-, vecinos también de La Zubia. Otros seis hombres se denominan Abençayde, residentes todos ellos en «Ugíjar la Baja».

Farax/Abenfarax: En los habices Farax es un vecino de La Zubia, en tanto que en el Apeo observamos dos vecinos varones que se denominan Abenfarax, residentes en «Ugíjar la Alta».

Foto: Aparece en tres hombres distintos en los habices de 1503, pero solo en un caso se especifica la vecindad en La Zubia. En el Apeo figura en tres vecinos de «Ugíjar la Baja».

Guadixi/Guadixia: «El Guadixi» aparece como lindero en los habices de I503, sin vecindad específica. Encontramos numerosos Guadixi en el Apeo, repartidos entre las alquerías de Los Ogíjares y Gójar. El nombre hace alusión a la ciudad de Guadix, en probable continuación de una nisba toponímica.

111. Peinado Santaella, Rafael: «Los Banu al-Qabsani: un linaje de la aristocracia nazarí», Historia. Instituciones. Documentos, 20 (1993), p. 338.

112. Espinar Moreno, Manuel: Libro de Apeo de la Zubia..., p. 189 
Magoni: Se presenta en los habices como vecino de Ugíjar, mientras que en el Apeo se concreta en individuos residentes en «Ugíjar la Baja» y «Ugíjar la Alta», Granada, Alfacar e Yjar. Esta última localidad debe de ser Híjar, otra de las alquerías de la Vega de Granada, a poco más de ro kms. al noroeste de La Zubia.

Malehe/Malehi/Malehí: Se repite tanto en los Libros de habices como en el Apeo en vecinos de La Zubia. Debe derivar de la referencia toponímica de La Malahá, alquería ubicada a unos $20 \mathrm{kms}$. al suroeste de La Zubia.

Monachili/Almonachili/Almonichili: Al igual que ocurre con Guadixi o Malehí, hace referencia directa a una localidad, en este caso el pueblo vecino de Monachil. Se repite en varios casos tanto en los habices como en el Apeo. Nos da una imagen de la movilidad asidua entre estas alquerías, tanto para el cultivo como para el establecimiento permanente, teniendo en cuenta que en el Apeo figuran al menos diez hombres distintos que comparten este nombre y que se cuentan entre los vecinos de La Zubia.

Moxcorrox/Moxcorroy/Moscorrox: En los habices se cita a Moxcorroy entre las lindes de un haza, sin especificar su vecindad. El nombre reaparece en el Apeo entre los vecinos de La Zubia.

Puxarry/Puxarri: Vecino de Ugíjar en los habices, mientras que en el Apeo figuran dos varones vecinos de La Zubia, y otro de «Dulcar». Debe de tratarse de Dúrcal, a unos $30 \mathrm{kms}$. al sur de La Zubia. Es muy probable que esta denominación derive de una referencia toponímica de las Alpujarras.

En cuanto a aquellos vecinos de La Zubia que aparecen en los habices como arrendadores en otras localidades, podemos destacar dos zonas de preferencia: la de Daralcohayle (Dar Alcohayli, Daralcohailí) y la de Dar Adefla (Adelfa). Estos nombres nos invitan a pensar que se trata de propiedades aristocráticas, incluso almunias. De momento no hay más datos sobre Dar Adefla, pero sí existe una casa de Daralcohayla en el Apeo. ${ }^{133}$ Parece que, aun estando dentro de los límites de La Zubia, tenían un estatus distinto al de la población. Podemos suponer que una parte de estas tierras, dependiente de una supuesta almunia, se hubiera entregado en determinado momento a un habiz. Hemos logrado encontrar en la cartografía parcelaria la referencia a un pago conocido como Arco Jaire, lo cual supone situar por vez primera este topónimo de forma precisa, al este del pago del «Miércoles por la mañana», muy cerca del cortijo Marín. ${ }^{\mathrm{II}}$

Por último, es necesario resaltar que aparecen muy pocos datos sobre oficios u otras actividades económicas en los habices vinculados a La Zubia. Está claro que buena parte de la población poseía o arrendaba tierras para su cultivo, y que ciertas figuras debían ocuparse de la almadraba. No obstante, se nombra al citado

113. Idem, p. 40

114. Véase Imagen 1. 
«alguasil» Alixbili, que podemos ver en algunas lindes de hazas, y un tesorero llamado Pero González, que seguramente adquiriera tierras en la zona tras la conquista.

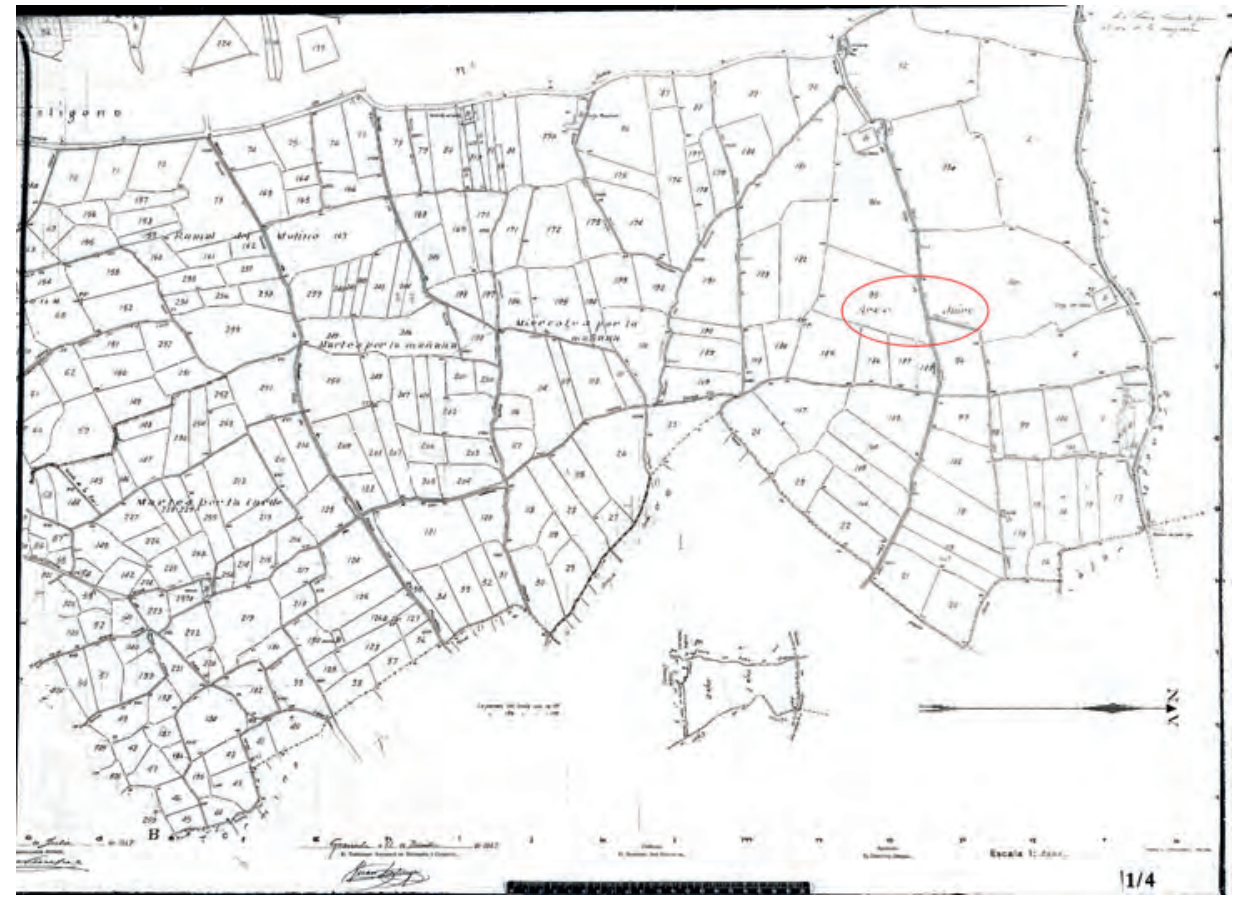

MAPA NACIONAL TOPOGRÁFICO PARCELARIO. PROVINCIA DE GRANADA. PARTIDO JUDICIAL DE GRANADA. TÉRMINO MUNICIPAL DE ZUBIA: POLÍGONO NÚM. 21947.

\section{CONCLUSIÓN}

Los habices granadinos conforman una fuente tan compleja como útil para los estudios socio-económicos del tránsito del mundo nazarí al castellano. Este somero análisis, tomando como punto de partida una única alquería, ha arrojado algunos datos de interés, que se verían multiplicados al incluir otras poblaciones en futuras investigaciones, y no digamos ya con un análisis pormenorizado de todos los pueblos de la Vega de Granada. La alquería de La Zubia se nos ha mostrado como un lugar de marcada densidad demográfica, preponderante sobre otras localidades de su alrededor, bien comunicada a nivel interno como externo, y con una cada vez más evidente presencia de propiedades aristocráticas y reales.

Una buena parte de la población debió de dedicarse al cultivo de la tierra, tanto en manos privadas como perteneciente a bienes habices, cuyas hazas no suelen ser demasiado extensas, encajando con la media que se encuentra en otras áreas periurbanas de la ciudad de Granada. Aunque debemos tomar con precaución los datos obtenidos, resulta interesante apuntar que cada haza de habiz solía rondar 
los 3 marjales y que se pagaba alrededor de 60 maravedís anuales por cada marjal. No podemos ignorar la ligera subida de la extensión de las hazas en La Zubia que se muestra entre los habices de 1503 y I505. La gran parcelación del terreno resulta evidente, lo que se corresponde, como vimos, con los datos obtenidos en otros estudios que se han acercado a la propiedad en Granada y su Vega, especialmente en el caso del cultivo de regadío. Junto a éste, propiciado por la buena red de acequias, debió de haber cierta presencia del secano y una parte menor del terreno dedicada a viñas y morales, aunque hoy por hoy resulta sumamente complejo conocer la proporción exacta entre dichos cultivos. La existencia de un horno y una almadraba nos permite acercarnos a otra faceta económica de la población, tan cercana a la capital del reino nazarí. No obstante, la información que nos ofrecen los Libros de habices en lo que se refiere a los oficios desempeñados por los habitantes de La Zubia y a los cultivos específicos de cada haza es escasa, si la comparamos con los datos que se conocen sobre otras alquerías.

Más allá de la información numérica, ha sido de gran interés reconocer algunos de los topónimos que encontramos en los habices en el posterior Apeo de La Zubia y en algunos casos, incluso, en mapas actuales, como el Pago de Corbales o el del Romizal. Haber situado, por ejemplo, Daralcohayle permitirá indagar sobre la naturaleza de este lugar en próximos estudios. Lo mismo ocurre con la rica información onomástica que facilita la creación de conexiones familiares, así como definir con mayor facilidad el estatus socio-económico de estos grupos, como en el caso de los Gazi.

Por otro lado, la persistencia en los apellidos de nombres de origen toponímico permite conocer algunos movimientos y asentamientos de personas o grupos foráneos en La Zubia y Los Ogíjares, dos alquerías que parecen estrechamente vinculadas en los Libros de habices de 1503 y 1505 . Normalmente, se trata de individuos que proceden (o sus antepasados) de alquerías muy cercanas o incluso limítrofes, como el caso de la vecina Monachil, aunque también nos encontramos algunos casos con procedencias geográficas más lejanas, como Guadix o Málaga. No podemos descartar que la cercanía a la capital del reino y las buenas condiciones para la explotación agraria ejercieran de foco de atracción de población foránea.

Para concluir, cabe añadir que se ha hecho evidente la necesidad de la comparación de fuentes diversas entre sí, como el empleo de cartografía antigua y la documentación escrita. Su combinación con la lectura bibliográfica y el empleo de nuevos medios técnicos como el uso del SIG (Sistemas de Información Geográfica) para ubicar pagos y procesar la cartografía antigua así como su parcelario, permitió recopilar y clasificar de la forma más completa posible la información obtenida a través de los habices. Con todo, las posibilidades que ofrecen estos Libros están lejos de agotarse, y más teniendo en cuenta que aún quedan algunos habices inéditos y sin estudiar. 


\section{FUENTES Y BIBLIOGRAFÍA}

Álvarez de Morales, Camilo: «Romanced Documents, Bilingual Documents and Books of habices», en Sijpesteıjn, Petra et.alli (eds.): Islamic History and Civilization: From Al-Andalus to Khurasan: Documents from the Medieval Muslim World. Tomo I, Leiden, Brill, 2007, pp. 3-23

Álvarez García, José Javier y García Porras, Alberto: «La zawiya del Cobertizo Viejo (Granada)», Anuario Arqueológico de Andalucía. Sevilla, Junta de Andalucía, 2003, pp. 429-436.

Ayuntamiento de La Zubia: Catálogo de Bienes y Espacios Protegidos, 2014.

Bearman, Peri et.alii: Encyclopédie de l'Islam. Vol. ir, Leiden, Brill, 2002.

Bernáldez, Andrés: Historia de los Reyes Católicos Don Fernando y Doña Isabel. Sevilla, Imprenta que fue de J.M Geofrin, I869.

Bresc, Henri, Guichard, Pierre y Mantran, Robert: Europa y el Islam en la Edad Media. Barcelona, Crítica, 200I.

CALERo, María Isabel: «Muhammad al-Ŷayyār, un alfaquí a través de los manuscritos de Cútar», en Echevarría Arsuaga, Ana (ed.): Biografías mudéjares o la experiencia de ser minoría: biografías islámicas en la España cristiana. Madrid, CSIC, Estudios onomásticobiográficos de al-Andalus, XV, 2008, pp. I5I-I74.

Carballeira Debasa, Ana María: «Aproximación a las donaciones piadosas en el Islam medieval: el caso de al-Andalus», en GARCíA LEAL, Alfonso (ed.): Las donaciones piadosas en el mundo medieval. Oviedo, Eujoa, 2012, pp. 385-406.

Carballeira Debasa, Ana María: «Pauvreté et fondations pieuses dans la Grenade nașride: aspects sociaux et juridiques», Arabica, 52 (2005), pp. 39I-4I6.

CARballeira Debasa, Ana María: Legados píos y fundaciones familiares en al-Ándalus (siglos IV/X-X-XII). Madrid, CSIC, Estudios Árabes e Islámicos: Monografías. 2, 2002.

CARrasco García, Gonzalo: «Huellas de la sociedad musulmana granadina: la conversión del Albayzín (I499-I500)», En la España Medieval, 30 (2007), pp. 335-380.

Carvajal López, José Cristóbal: La cerámica de Madinat Ilbira (Atarfe) y el poblamiento altomedieval de la Vega de Granada. Granada, Arqueología y Cerámica, Grupo de Investigación Toponimia, Historia y Arqueología del Reino de Granada, 2008.

Castillo Ruiz, José, Martínez Hidalgo, Celia y Pérez Córdoba,Gloria: «El sistema histórico de riego de la Vega de Granada. Reconocimiento y protección desde la perspectiva del Patrimonio Agrario», en SANChis-IBOR, Carles; et al. (eds.): Irrigation, Society and Landscape. Tribute to Thomas F. Glick. Universidad Politécnica de Valencia, Valencia, 20I4, pp. 763-789.

CoHen, Mark: Poverty and Charity in the Jewish Community of Medieval Egypt. Nueva Jersey, Princeton Univeristy Press, 2005.

Cohn-SHerbok, Dan: Breve enciclopedia del judaísmo. Madrid, Itsmo, 2003.

Coleman, David: Creating Christian Granada: Society and Religious Culture in an Old-World Frontier City, I492-I600. London, Cornell University Press, 2003.

Espinar Moreno, Manuel. «Consideraciones sobre el regadío en la Vega de Granada. Repartimientos musulmanes (siglos XII-XVI)», Chronica Nova, I8 (I990), p. I2I-I53.

Espinar Moreno, Manuel: Libro de de la Zubia en I570. Estudio y transcripción. Granada, Libros EPCCM, 2015.

EsPinar Moreno, Manuel: «Notas sobre la alquería de Cájar (I505-I547)», en CEMyCTH, $\mathrm{n}^{\mathrm{o}} \mathrm{I} 4-\mathrm{I} 5, \mathrm{I} 985-\mathrm{I} 987, \mathrm{pp} .47-60$. 
ESPINAR Moreno, Manuel: «Noticias para el estudio de la alquería de Gójar. Bienes habices», Cuadernos de Estudios Medievales y Ciencias y Técnicas Historiográficas (CEMyCTH), $\mathrm{n}^{\mathrm{o}}$ IO-II (I983), pp. I05-I48.

Frenkel, Yehoshua: «Piety and Charity in Late Medieval Egypt and Syria», en FRENKEL, Miriam y LEV, Yaacov (eds.): Charity and Giving in Monotheistic Religions. Berlín, Walter de Gruyter, 2009, pp. I75-203.

Galán SÁnchez, Ángel y Peinado Santaella, Rafael: Hacienda regia y población en el Reino de Granada: la geografía morisca comienzos del siglo XVI. Granada, Universidad de Granada, I997.

GaRcía SANJuÁn, Alejandro: Hasta que Dios herede la tierra. Los bienes habices en al-Andalus (siglos $X-X V)$. Huelva, Universidad de Huelva, 200.

GARRIDo AtIENZA, Miguel: Las capitulaciones para la entrega de Granada. Granada, Imprenta de Paulino Ventura Traveset, I9Io.

Hennigan, Peter: The Birth of a Legal Institution. The Formation of the Waqf in Third-Century A.H. Hanafī Legal Discourse. Leiden, Brill, 2004

Hernández Benito, Pedro: «Alcabalas y diezmos. Economía y estructura del poblamiento en la Vega de Granada a través de las fuentes fiscales castellanas (I5OI-I506)», Arqueología y territorio medieval, 3 (1996), pp. 65-90.

Hernández Benito, Pedro: La Vega de Granada a fines de la Edad Media según las rentas de los habices. Granada, Diputación Provincial de Granada, I990.

Holman, Susan: «The language of social justice in early Christian homilies», en FrENKEL, Miriam y LEV, Yaacov (eds.): Charity and Giving in Monotheistic Religions. Berlín, Walter de Gruyter, 2009, pp. 89-III.

JimÉnez MATA, María Carmen: La Granada islámica. Contribución a su estudio geográficopolítico-administrativo a través de la toponimia. Granada, Universidad de Granada, 1987.

Kochuyt, Thierry: «God, gifts and Poor People: On Charity in Islam», Social Compass, 56, I, (2009), pp. 98-II6.

LADERO QUeSADA, Miguel Ángel: «Mudéjares y repobladores en el Reino de Granada (I485I50I)», Cuadernos de Historia Moderna, I3 (1992), pp. 47-7I.

LETHEM IвRAHIM, Barbara: «Arab Philantropy in Transition», en LeTHEM lbRAHIM, Barbara y SHERIF, Dina (eds.): From Charity to Social Change. Trends in Arab Philanthropy. Nueva York, The American University in Cairo Press, 2008, pp. I-23.

LEv, Yaacov: «The Discourse of Charity and Piety in Medieval Arabic Literary Sources», en CARballeira Debasa, Ana María (dir.): Caridad y compasión en biografías islámicas. Madrid, CSIC, 20II, pp. 67-82.

Maíllo SAlgado, Felipe: Los arabismos del castellano en la Baja Edad Media. Consideraciones históricas y filológicas. Salamanca, Universidad de Salamanca, I998.

Malpica Cuello, Antonio, et.alii: Historia de Granada. Granada, Proyecto Sur, 1996.

Marín Fernández, José: Historia de La Zubia de José Marín. La Zubia, Asprogrades, 2013.

Martínez Peñas, Leandro y Fernández Rodríguez, Manuel: La guerra y el nacimiento del Estado Moderno. Consecuencias jurídicas e institucionales de los conflictos bélicos en el reinado de los Reyes Católicos. Valladolid, Asociación Veritas para el Estudio de la Historia, el Derecho y las Instituciones, 2014.

Martínez Vázquez, Luis: La Vega de Granada. Transformaciones y cambio de los paisajes entre el Reino Nazarí y el Reino de Granada. Granada, Universidad de Granada, 2015.

Meri, Josef (ed.): Medieval Islamic Civilization. An Encyclopedia. Nueva York, Routledge, 2006.

Moral, Celia del: «Jardines y fuentes en al-Andalus a, través de la poesía», MEAH, 58 (2009), pp. 223-249. 
O'Callaghan, Joseph: The Middle Ages Series: The Last Crusade in the West: Castile and the Conquest of Granada. Philadelphia, University of Pennsylvania Press, 2014.

Peinado Santaella, Rafael: «Los Banu al-Qabsani: un linaje de la aristocracia nazarí», Historia. Instituciones. Documentos, 20 (I993), pp. 313-353.

Pocklington, Robert, «Lexemas toponímicos andalusíes», Alhadra. Revista de la Cultura Andalusí, 2 (2016), pp. 233-321.

Poutrin, Isabelle: «Los derechos de los vencidos: las capitulaciones de Granada (I49I)», Sharq al-Andalus, I9 (2008-2010), pp. II-34.

Pulgar, Hernando del: Crónica de los señores Reyes Católicos Don Fernando y Doña Isabel de Castilla y de Aragón. Valencia, Imprenta de Benito Monfort, I780.

Quevedo, Amalia: Mendigos ayer y hoy. Madrid, Ediciones Internacionales Universitarias, 2007.

Salvá, Miguel y Sainz de Baranda, Pedro: Colección de documentos inéditos para la Historia de España. Tomo XI. Madrid, Imprenta de la viuda de Calera, I847.

Seco de Lucena, Luis, «Toponimia árabe de la Vega y los Montes de Granada», Al Andalus, 29, (I964), pp. 3II-327.

Singer, Amy: Charity in Islamic Societies. Cambridge, Cambridge University Press, 2008.

Torres, Alonso de: Chronica de la Santa Provincia de Granada, de la regular observancia de N. Serafico Padre San Francisco. Madrid, Impresor Juan García Infançon, I683.

Trillo SAN José, Carmen: «Agentes del estado y mezquitas en el reino nazarí», Historia. Instituciones. Documentos, 34 (2007), pp. 279-29I.

Trillo SAN José, Carmen: «El Nublo, una propiedad de los infantes de Granada», Homenaje al profesor José María Fórneas Besteiro. Vol. 2, I995, pp. 867-879.

TRILlo SAN JosÉ, Carmen: «El tiempo del agua. El regadío y su organización en la Granada islámica», Acta historicaet archaeologica mediaevalia, 23-24, (2002), pp. 237-286.

TRILlo SAN José, Carmen: «Propiedad aristocrática en el reino nazarí de Granada (siglos XIII-XV): almunias versus alquerías» [En prensa]

Trillo SAN José, Carmen: Agua, tierra y hombres en al-Andalus. La dimensión agrícola del mundo nazarí. Granada, Ajbar, 2004.

Trillo SAN JosÉ, Carmen: La Alpujarra antes y después de la conquista castellana. Granada, Universidad de Granada, I994.

Trillo SAN José, Carmen: La Alpujarra medieval según las rentas de los bienes habices. Granada, I988.

Trillo San José, Carmen; Hernández Benito, Pedro: «Topónimos de la Alpujarra según un manuscrito de rentas habices», Miscelánea de estudios Árabes y Hebraicos (MEAH), $\mathrm{n}^{\mathrm{o}} 37$, I (1994), pp. 285-306.

VAllvé Bermejo, Joaquín: Al-Andalus: sociedad e instituciones. Madrid, Real Academia de la Historia, I999.

VIDAL CASTRO, Francisco: «El agua y los arabismos en español. Relación de los principales vocablos», en Castillo Castillo, Concepción et.al. (coord.): Homenaje al profesor José María Fórneas Besteiro. Universidad de Granada, Granada, I995, pp. 529-547.

Villanueva Rico, María del Carmen: Casas, mezquitas y tiendas de los habices de las Iglesias de Granada. Madrid, Instituto Hispano-Árabe de Cultura, I966.

Villanueva Rico, María del Carmen: Habices de las mezquitas de la ciudad de Granada y sus alquerías. Madrid, Instituto Hispano-Árabe de Cultura, I96I. 

Calidad de Revistas

científicas Españolas

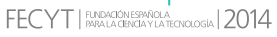

SERIE III HISTORIA MEDIEVAL

REVISTA DE LA FACULTAD DE GEOGRAFÍA E HISTORIA
AÑO 2018

ISSN: 0214-9745

E-ISSN 2340-1362

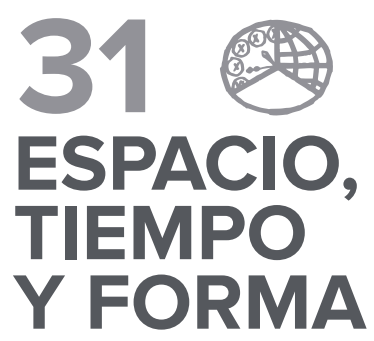

GREGoRIO DEL SER QUIJANO

Carmelo Luis López, In Memoriam

\section{Artículos · Articles}

29 SOHA ABBOUd Haggar

Un resumen del tratado jurídico de Al-Tafrí: el Manuscrito Árabe 1233 del Monasterio de El Escorial y su supuesta relación con Leyes de Moros

EDUARDo Aznar VALLejo

Norma y conflicto en la navegación castellana bajomedieval

69 Carlos Barquero Goñ

Transferencias de recursos de la Orden de San Juan desde España hasta el Mediterráneo Oriental durante la Edad Media

\section{Margarita Cabrera Sánchez}

La muerte del príncipe Don Juan. Exequias y duelo en Córdoba y Sevilla durante el otoño de 1497

\section{Francisco de Paula Cañas Gálvez}

Primogenitura, continuidad dinástica y legitimitad instituciona en Castilla a principios del siglo XV: Catalina de Trastámara, Princesa de Asturias (1422-†1424)

\section{Paloma Cuenca Muñoz}

El códice visigótico de los Moralia in lob, ms. lat. 83 de la John Rylands Library de Manchester

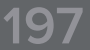

\section{JOSÉ MARÍA DIAGO JIMÉNEZ}

Las instituciones educativas de carácter religioso en el reino hispanovisigodo de los siglos VI y VII a través de los cánones conciliares y las reglas monásticas

MARÍA Díez Yáñez

La Ética aristotélica en Castilla: las bibliotecas universitarias medievales y prerrenacentistas

\section{Estefanía Ferrer del Río}

Rodrigo de Mendoza, I Marqués del Cenete y I Conde del Cid: paralelismos entre su biografía y su pretendida genealogía

\section{ALEJANDRo García Morilla \\ Escritura publicitaria de transición: entre la visigótica y la carolina.} El paradigma burgalés

María Dolores García Oliva

Señores contra campesinos: un conflicto por la tierra en Mirabel a finales de la Edad Media y principios de los Tiempos Modernos (1488-c. 1520)
34.3 jaime García Carpintero lópez de Mota

La hospitalidad santiaguista a finales de la Edad Media: el proyecto de reconstrucción del hospital de Alarcón

377 LAURA DA GRACIA

La posesión agraria individual en los registros notariales de Fuente el Sol (1481-1482

4.03 Mauricio Herrero Jiménez

El valor de los documentos reales en los procesos de la Real Chancillería de Valladolid

4.31 Miguel josé López-Guadalupe Pallarés

Procesos de señorialización en los concejos de la Extremadura castellano-leonesa. Un estado de la cuestión

455 Ángel Martínez Catalán

Las rentas decimales del cabildo catedralicio de Cuenca a inicios del siglo XV (1400-1432)

4.83 Gonzalo Oliva Manso

Cien años de moneda en Castilla (1172-1268). El siglo del maravedí de oro

521 jesús Olivet García-Dorado

El cabildo de curas y beneficiados de Toledo en la segunda mitad del siglo XV. Composición y aspectos institucionales (1455-1488)

547 Mariel PÉrez

Clérigos rurales, comunidades y formación de las estructuras parroquiales en la diócesis de León (siglos XI-XIII)

575 Milagros Plaza Pedroche

La Orden de Calatrava en la Baja Edad Media (1350-1500): repaso historiográfico

597 Pedro Andrés Porras Arboledas

La pervivencia del Fuero de Cuenca en los inicios de la Modernidad: el testimonio de los fueros de Consuegra y Requena

619 Juan Pablo Rubio Sadia

Los mozárabes frente al rito romano: balance historiográfico de una relación polémica

SANDRA SUÁREZ GARCíA

Los habices de la Vega de Granada como forma de conocimiento del reino nazarí y su transformación tras la conquista: la alquería de La Zubia 


\section{1}

\section{ESPACIO,}

\section{TIEMPO}

\section{Y FORMA}

SERIE III HISTORIA MEDIEVAL

REVISTA DE LA FACULTAD DE GEOGRAFÍA E HISTORIA

\section{De medievalistas ilustres · On Renowned Medievalists}

671 Francisco Abad Nebot

Entradas para un Diccionario

\section{Libros $\cdot$ Books}

679 Almagro Vidal, Clara, Paisajes medievales en el Campo de Calatrava (CARLos BARQUero GoÑI)

681 Carvajal Castro, Álvaro, Bajo la máscara del Regnum. La monarquía asturleonesa en León (854-1037) (JOSÉ MANUEL RODRÍGUEZ GARCíA)

683 Fuente Pérez, María Jesús, Violante de Aragón, reina de Castilla (ANA ECHEVARRía ARsuaga)

687 Martín Prieto, Pablo, Historia del pensamiento medieval: filosofia y teología (FRANCISCO LEÓN FLORIDO)

689 Pardo de Guevara y Valdés, Eduardo (ed.), Mujeres con poder en la Galiciamedieval (siglos XIII-XV). Estudios, biografías y documentos (ENRIQUe CANTERA MONTENEGRO)

693 Ríos Saloma, Martín (ed.), El mundo de los conquistadores (Jessica Ramírez MéndeZ)

690 Solórzano Telechea, Jesús, Arízaga Bolumburu, Beatriz y BOCHACA, Michel (eds.), Las sociedades portuarias de la Europa atlántica en la Edad Media (ANTONIO ORTEGA VILLOSLADA)

703 VAL VALDIVIEso, María Isabel del (coord.), El agua en el
imaginario medieval. Los reinos ibéricos en la Baja Edad Media (MARÍA Jesús Fuente)

707 Villar García, Luis Miguel, Archivo Municipal de Segovia. Documentación medieval, 1166-1474 (ENRIQUE CANTERA MONTENEGRO) 